This is a reprint from a paper published in the Proceedings of the IADIS International Conferences IADIS,http://www.iadis.org 


\title{
WEB-BASED SUPPORT FOR CREATIVE COLLABORATION
}

\author{
Alastair Weakley, Ernest Edmonds \\ Creativity \& Cognition Studios \\ Faculty of Information Technology \\ University of Technology, Sydney \\ Australia
}

\begin{abstract}
This paper considers the opportunities presented by Web-based systems for the support of groups involved in work of a creative nature. In particular, it is concerned with the sharing of knowledge that might otherwise remain unspoken, or tacit, amongst those engaged in design tasks. A prototype system has been developed and this system, together with its evaluation, is described. Drawing on the results of the evaluation, pointers for further development are presented.
\end{abstract}

\section{KEYWORDS}

Creative collaboration, web-based community, creativity, design.

\section{INTRODUCTION}

This paper is concerned with the ways in which we can capitalize on the opportunities for supporting creative work offered by Web-based community support systems. We also consider some limitations of such systems in the domain of creative collaboration and how these might be overcome.

John-Steiner (2000) has found that, despite our tendency to think of creative work as being the pursuit of the solitary individual, in fact: [g]enerative ideas emerge from joint thinking, from significant conversations, and from sustained, shared struggles to achieve new insights by partners in thought. Meanwhile, Edmonds et. al. (2002) note that in the case of digital arts, the tendency for artists to collaborate with others in order to access skills and expertise has generally been increasing since the field's inception in the 1960s. Going further, Fischer (2000) tells us that creative activity grows out of an individual's relationship with their work and with other people, he notes that the power of the unaided individual mind is highly overrated. We have clear indications, then, that teamwork and collaboration can be an important part of creative work.

In the work described here, we have chosen design as the task domain. The word 'design' can be used to cover a vast swathe of human activity. In this case, following Papanek (1972), we adopt the broad definition of design as: the planning and patterning of any act towards a desired, foreseeable end. Our designers, typically working in groups, would be engaged in the solution of a specific problem; for example the development of a new product. In this sort of work it is normal that while consecutive projects may have common characteristics, each one is unique. In the area of design research, these sorts of problems have often been described as 'wicked' and it is generally accepted that, at the start of the process, they are illdefined. Lawson (1990) points out that rather than one following logically upon the other, it is central to modern thinking about design that problems and solutions are seen as emerging together. Gross calls this a process of incremental formalisation (Gross, 1996).

This formalisation process may be based on a series of decisions that the designer makes as the project progresses. Of course, as new information comes to light, the reasons behind earlier decisions may need to be revisited and reviewed. This reviewing process is made easier if a record of past decisions has been kept. Carrol and Moran (1991) present several additional reasons for recording the design rationale: (a) to support reasoning processes in design, (b) to facilitate communication among the various players in the design 
process (designers, implementers, maintainers, users etc.) and (c) to further the cumulation and development of design knowledge across design projects and products.

Design, in our sense, clearly involves a considerable amount of investigation and learning. Indeed, it is common for designers such as those we describe, to spend a substantial amount of time researching the problems they are faced with and building collections of useful resource material. We present below a system that has been developed to support the gathering and organization of such collections of resource material. Our system goes further, however. One hypothesis that the work described aims to test is that making the collections public within the community or organization will allow the sharing of knowledge and expertise that otherwise would remain tacit. Polanyi (1966), in an extended discussion on tacit knowledge, points out that we can know more than we can tell. In one example he suggests that while one might be able to recognize a familiar face in a crowd, it is not always possible to explain how we recognize a face that we know. Polanyi's tacit knowledge, then, is knowledge or expertise that cannot be articulated. In this paper, we are interested in sharing knowledge that includes but is not limited to the Polanyian tacit knowledge. In the work described here, we are interested in sharing knowledge and expertise that would normally remain unarticulated either because we cannot do so or because it is not considered relevant in a particular context. Our evaluation of the prototype system has shown that it is indeed possible to expose and share such knowledge. Moreover, it has exposed areas where systems supporting community or team-formation could be further enhanced.

\section{BACKGROUND}

Among a wide range of other opportunities, modern communications technology has brought us the chance of developing and maintaining relationships with people whom we may never, or only rarely, physically meet. Nowhere is this more evident than in the World Wide Web where, increasingly, we find communities of individuals coming together for work or leisure. Of course, such Web systems, as with any technology, have their limitations. In this section we investigate the implications of both these opportunities and limitations for Web-based creative collaboration.

In many cases, the communities and groups that form online are bound together by some common interest and not a common location: a mental proximity of some sort rather than a physical one. Gongla and Rizzuto (2001) describe what is required for the ties that bind individuals into a community to form: Each person looks at the others and seeks to answer the very basic question, namely: Who are you?....For the potential community to form, the collective answer to that question of 'Who are you?' must be: 'You are like me.' In addition to the question 'who are you?' designers as described above are very much concerned with the question 'what do you know?'. As Fischer (2000) points out, it is seldom the case that a single person has all the skills required to complete a complex design project without seeking expert help in certain areas and it is the location of and access to such expertise that is one of the concerns here.

Next we will consider the different levels at which people may work together and how well these mesh with levels of communication offered by current technologies. John-Steiner (2000) presents four modes of collaboration among people engaged in creative work:

-Distributed collaboration: characterized by participants who are linked by similar interests. Roles are often informal and fluid but John-Steiner notes: out of such informal connections some lasting partnerships may be built.

- Complementary collaboration: characterized by a division of labour based on complementary expertise, disciplinary knowledge, roles and temperament. As Mamykina et. al. (2002) point out, the multidisciplinary nature of such collaborations can be particularly advantageous as the partners may help each other to see new possibilities and step out of their familiar territory.

-Family collaboration: John-Steiner describes this type of relationship as a dynamic integration of expertise, painting a picture of relationships that are at once fluid and intense.

-Integrative collaboration: here the joining of forces between the collaborators forces major changes which they might be unable to bring about alone. Integrative partnerships are motivated by the desire to transform artistic knowledge, thought styles, or artistic approaches into new visions. 
Distributed collaboration, as John-Steiner points out, may occur in online communities and is exemplified in communities where communication is asynchronous and text-based. With mixed membership, the division of labour associated with complementary collaboration also could be well supported by current technologies. However, it is when we start to consider the dynamic and closely-coupled nature of the family and integrative styles of collaboration that current technologies start to look weak. Figallo (1998) categorizes current online communities by the level of interactivity between their members:

-In a shrine, visitors come to collect facts or data about some object of interest: while the visitors may all have the same interest, they seldom communicate with one another.

-Theatres are places where a few people actively contribute but many more merely observe

- Cafes are places driven by the energy of conversation and exchange, where relationships are continuously forming, growing, and, occasionally, blowing up

The cafe style of online community comes closest to fully supporting an integrative style of creative collaboration. However a question remains as to whether such closely-coupled work could be truly supported. Mamykina et. al. (2002) discuss the need for fluid and open communication between creative partners but much of human communication is non-verbal. As, for example, Sperber and Wilson (1986) have pointed out, a single sentence, with a single semantic representation, can express an unbounded range of thoughts. The meaning of the verbal utterance is inferred by the listener who may draw partly on experiences he or she shares with the speaker as well as from the speaker's facial expression, posture, gestures and so on. In common Web-based systems, which typically transmit only a portion of the conversational data, it can be hard to establish the level and nature of common experience at the start of a relationship. In their experiments, Olson and Olson (2000) found that sustaining a working relationship between participants who had never had the opportunity to meet in person and to establish the level of this shared experience or common ground was particularly difficult. Çakir (2002) suggests that virtual meetings between people communicating at the same time but from different places across the globe may be impossible to achieve because the same time is not necessarily contemporaneous for all participants. For the widely distributed groups that Çakir describes the experience of participating in a real-time exchange is unlikely to be equal for all group members. Again this, as well as cultural and language differences, affected the groups that Olson and Olson studied. They suggest that, in addition to high levels of common ground, groups need to be engaged in loosely coupled work in order to succeed with remote technology.

In a discussion on the nature of 'place', Meyrowitz (1985), drawing on the work of Goffman, makes some interesting points that are particularly relevant to this discussion. He points out that human interaction occurs in a 'place' but that the boundaries of such a 'place', rather than being the physical objects we commonly imagine such as walls, doors and so on, are created by 'barriers to perception'. Bearing this out, Harrison and Dourish (1996) make a distinction between a 'space' and a 'place': [s]pace is the opportunity; place is the understood reality. Meyrowitz goes on to describe ways in which a 'place' may change: for example when someone new walks into a room and how this in turn may force us to moderate our behaviour. It is significant to note that online, Web-based 'places' can be created that do not change in this way: access to a system can be strictly controlled and, where necessary or desirable, anonymity can be preserved. Other researchers, too have found that the world of the virtual community may be closer to idealised notions of 'community' than our present-day real-world communities (Shumar and Renninger, 2002). It seems that, while one would be hard-pressed to argue with the analysis presented by, for example, Dreyfus (2001) or Graham (1999) that disembodied, technologically-mediated communication is necessarily inferior to the 'real thing' there are nevertheless a number of ways in which it can be considered to be more 'real' and more effective.

Hollan and Stornetta (1992) suggest that, rather than trying to develop online systems that slavishly mimic real-life interaction, we should strive to exploit the unique opportunities that such systems can offer. Rather than trying to make systems that fake the effect of 'being there' we should create systems that offer new facilities: ones that we might continue to use even when working together face-to-face. We describe below a system that has been developed to address some of the requirements of creative collaboration in the domain of design. Rather than attempt to recreate face-to-face interaction, this system instead embodies some of the unique properties that future online systems might offer. 


\section{IMPLICATIONS FOR SUPPORT SYSTEMS}

The foregoing discussion has attempted to draw together aspects from a wide range of existing research that are particularly relevant to creative work. As we have seen, John-Steiner points to the dynamic integration of expertise as an important factor in the closer types of creative collaboration and it has been suggested that this may be brought about by fluid and open communication (Mamykina et al., 2002). Olson and Olson suggest, though, that unless we can establish a high level of common ground, our efforts at remote collaboration may never succeed. These close collaborative relationships are based on mutual respect and trust (Mamykina et al., 2002).

Kollock (1999) has suggested that one factor which can engender commitment to an online community and trust in the people we meet there is persistence of members' identity. Where we can identify a person's activities within the group over time, we can repay favours and build long-term relationships. As Meyrowitz has pointed out, we may adopt different personae in different places and therefore consistency in our sense of 'place' is important.

We can therefore start to compile a list of desirable characteristics of Web-based support systems for creative collaboration as follows:

-Support for synchronous communication- this should include support both for verbal and nonverbal communication

-Support for the establishment of common ground

-A way of establishing trust between users

-A way of recording and reviewing past decisions

-A stable identity for group members

-A user profiling system for finding suitable collaborators- some way of establishing who knows about what

-Support for the development and sharing of prototypes

A prototype system has been developed embodying some of the characteristics listed above. In the domain of design, the system is aimed at facilitating the creation of collaborative partnerships as well as supporting the generation of new associations leading to creative work. The system does not at present incorporate facilities for direct person-to-person communication whether synchronous or asynchronous. However, it has shown some promise as a means of sharing tacit knowledge about 'who knows what' and establishing common ground. It also embodies facilities for recording past work and reviewing these recordings. It is possible to identify the actions of individual users of the system and, in the limited domain of organizing snippets of research material, the system aims to facilitate the sharing, and the shared development of prototypical groupings and layouts.

\section{THE PROTOTYPE SYSTEM}

One aim of the work described here, and the one that is particularly relevant to this paper, is to help creative knowledge-workers find potential collaborators and to help them establish common interests and, more generally, common ground for their working relationships. The system also aims to support the sharing of knowledge that might otherwise remain tacit. 


\subsection{Description of the Prototype}

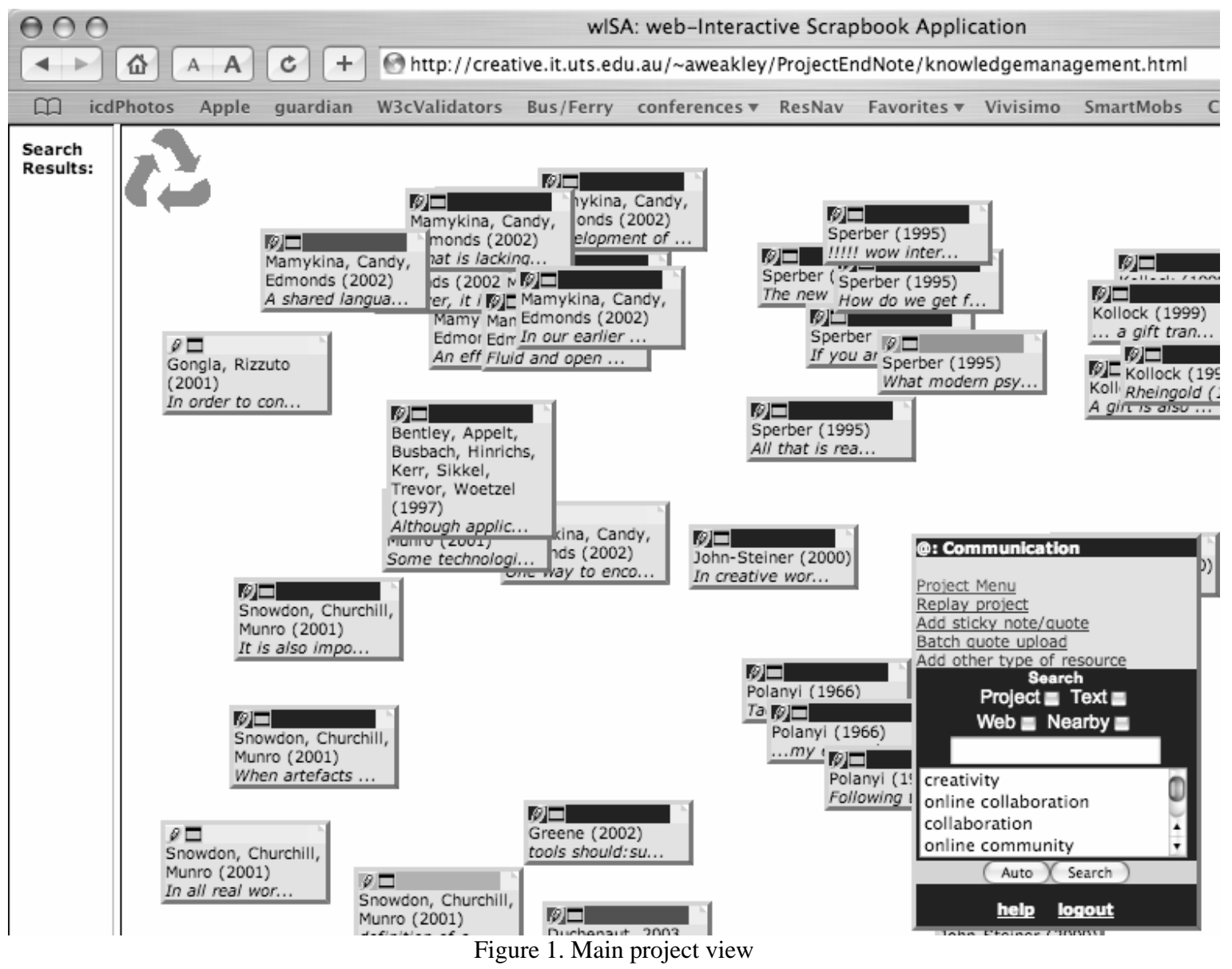

wISA, the web-Interactive Scrapbook Application, is a prototype system that has been developed in order to address and investigate some of the issues described above. Implemented using PHP, MySQL, HTML and JavaScript, it can be viewed with a normal Web browser. Users of this online system may make collections of useful resources that might include textual notes, pointers to other Web sites, files or images that they can upload into the system or references to people who might prove useful in their current project. The resources are represented graphically as small tiles in the browser window and, like cuttings in a conventional paper scrapbook, can be physically arranged and grouped as desired by dragging and dropping. Figure 1 shows a typical project; a number of resource objects have been created by the user and arranged to their liking. The aim of this is to allow the designer to think visually as their work develops. As Yamamoto et. al. (Yamamoto et al., 2000) argue: two-dimensional (2D) positioning of objects serves the same purpose as sketching does for domains where no sketches exist: while it is clear that research and investigative activities form an important part of the design process they are not easily represented by sketches. At the top of each resource object is a button that opens an editing page so the resource can be annotated or its contents can be changed.

Each user may create any number of 'projects'; each one the equivalent of a page in a paper scrapbook. The contents of every project are visible to all users of the system but are not otherwise publicly available. Where projects are shared between a number of users, any of them can add or remove resources as well as annotating them and modifying the spatial arrangement. It is possible to search within the system's database for new and interesting material. In addition to simple, keyword-based searching for individual resources, it is possible for the results to be displayed as a list of other users' projects that contain resources matching the query. When this produces too long a list of results, the user may specify that only resources that have been 
placed physically near to those matching the query should be displayed. In this way, it is possible to see where other users of the system found relationships between resources one is specifically looking for and others one might not otherwise have considered. In addition it is possible to see who created the resource originally and who has annotated it and what comments were made. It is by giving access to these sorts of information, which would normally remain unarticulated, that the system attempts to facilitate the sharing of tacit knowledge among its users.

In the wISA system, in order to capture the rationale behind the development process, the spatial locations of resources are recorded over time as the project develops. Users may replay their own or other's projects at any time. When a project is replayed, the recorded movements of the resources are re-enacted dynamically: they appear on screen and move about as they did when the project was created. An indication is also given as to which user made each move.

In the next sections we present the results of an evaluation of the prototype that has been carried out. The prototype, in that it supports spatial positioning of objects, bears some resemblance to what have become known as spatial hypertext systems. In the area of spatial hypertext research, Shipman (2001) has pointed out that measuring the expressive and communicative power of these systems is particularly difficult. However, Shneiderman (2002) presents eight 'tasks to support creativity' that could be used as the basis for an evaluation for a system, such as wISA, aimed at the support of creative work. Shneiderman's tasks are as follows: (1) searching and browsing digital libraries, the Web and other resources; (2) visualizing data and processes to understand and discover relationships; (3) consulting with peers and mentors for intellectual and emotional support; (4) thinking by free associations to make new combinations of ideas; (5) exploring solutions- what-if tools and simulation models; (6) composing artefacts and performances step-by-step; (7) reviewing and replaying session histories to support reflection; (8) disseminating results to gain recognition and add to the searchable resources. The overall aims of the wISA system in the areas of sharing tacit knowledge, recording design rationale, searching for new information and visual representation and manipulation of data mesh well with Shneiderman's tasks. It would therefore be appropriate to base an evaluation of such a system on Shneiderman's work.

\subsection{Evaluation of the Prototype}

An internationally distributed group of seven researchers was divided into two teams, each team was asked to imagine that they were preparing a paper for a conference on human-computer interaction. Over the course of three days they were required to use the wISA system to start to collect and organize relevant quotations and other material for their imaginary paper. Some relevant resources had been entered into the system beforehand and the researchers were, of course, free to add new material as they chose. Although not all the evaluators knew all of the others, they all knew at least some of the others and in some cases they had worked together previously.

At the end of the evaluation period, the evaluators were asked to complete a questionnaire comprising 43 questions divided into groups corresponding with Shneiderman's eight tasks as described above. For each question the respondents were asked to choose one of five options typically ranging from 'very effectively' to 'not at all effectively'. Each option was given a score between four and zero, the overall value for each question was found by taking the mean score of the responses. The evaluators were also given ample opportunity to make comments. In addition, data recorded within wISA itself, notably comments made by the evaluators, was available for analysis.

\subsection{Results of the Evaluation}

Here we discuss the most significant evaluation results.

The wISA system was found to support 'learning about the thoughts and ideas of others' with a score of 2.7 out of 4. One user made the comment that: "the sources available in this project and the others have made me realise that I should be talking more with [name] about collaboration environments...." and went on to say: "just starting- finding the amount of existing material hard to navigate- useful though for the real work I am currently doing!”. This is a clear indication that this sort of environment, which facilitates searching within the work of others, supports the exchange of tacit knowledge. It is important to note, however, that, when the evaluators were asked who they would be prepared to share their material with, it 
became clear that privacy of information is an important issue in this sort of system. All of the evaluators of the system knew at least some of the others before the evaluation began and, during the course of the evaluation, they were able to identify one another's contributions and actions. While it was clear that, within the current group, the users would be prepared to share their resources they would not be keen to make them more widely available. More than one evaluator noted that the type of information that they had entered into the system would affect their decision, and it seems reasonable to suppose that the scope of sharing would affect the information they would consider inputting. A typical comment was: "The sharing of ideas and notes is fine provided you either know who you are working with or have a common goal or target”. It would seem, then, that access to such a system would have to be restricted to people working within the same organization or on the same project. Another of the evaluators raised the issue of intellectual property: even within the same organization, privacy of information can be an issue, and indeed amongst members of the fluid product development teams described above this is likely also to be the case.

It is also interesting that the evaluator quoted above raised the issue of knowing who they were working with. We have clearly seen the establishment of increased common ground in the case of the user described above who realized they had an interest in common with one of the others. It seems likely that the relatively low score for the question: Bearing in mind that you knew each other beforehand, do you think you learned new things about the other people in the group and their skills and expertise?, which was only 1.5 out of 4 , was due to the fact that the task in hand was only directly related to a few of the evaluators' real work or interest.

The majority of people felt that features such as email messaging and voice communication should be integrated into wSIA (score 3.5 out of 4). Nevertheless, the facility for spatial arrangement of objects on the page was found to be useful (score 3.1 out of 4). While there was a bias towards using email instead of wISA for this collaborative writing task (score 2.7 out of 4) the unanimous feeling of the evaluators was that they would neither prefer to have a text-only display of the information, nor would they like to additionally have a text-only display of the information. Clearly, the dynamic spatial arrangement of resources facilitated by this system offers some advantages for the type of creative work in question.

We have seen indications that the wISA system can support the exchange of knowledge and expertise that might otherwise remain tacit. It would be useful to carry out further evaluations of such a system, this time with a broader group of users engaged in their normal day-to-day activities. We have here exposed some aspects of the current system, such as control of access to information and support for direct communication between users that should be addressed in order for future evaluations to be even more effective. In the wISA system, communication is restricted to a great degree. The results of the evaluation described here provide a useful base point for future investigations into the effectiveness of systems offering additional features such as direct interpersonal communication and more sophisticated data-access control. By adding features one-by-one, it will be possible to see how they change the ability of the system to fulfil its aims of facilitating the creation and sustainment of collaborative partnerships.

\section{CONCLUSION}

The work described here has raised issues about how to control access to collections of information contained within wISA so that they can at once be publicly available to others within an organisation or community and at the same time be sufficiently private that users will not feel inhibited in their use of the system. Nevertheless, we see a clear indication that systems such as wISA, which allow access to collections of information made by others, can facilitate the sharing of tacit knowledge. In turn we identify this as an important aspect of establishing common ground and forming working relationships as part of the process of building creative communities and supporting creative collaboration.

\section{ACKNOWLEDGMENTS}

Special thanks are due to Brigid Costello of Creativity \& Cognition Studios for her excellent editorial advice. Some of the background work presented here was carried out with the support of the EPSRC as part of the COSTART2 project at Loughborough University, U.K., grant title: Computer Systems for Creative Work: 
An Investigation of Art and technology Collaboration. Grant Reference: GR/N26272/01. See Internal Report Number 9.

\section{REFERENCES}

Çakir, A. E. (2002). Virtual communities - a virtual session on virtual conferences. In Behavior \& Information Technology, 21, 365-371.

Carrol, J. and Moran, T. (1991). Introduction to This Special Issue on Design Rationale. In Human-Computer Interaction, 6.

Dreyfus, H. L. (2001). On the Internet: Thinking in Action. Routledge, New York.

Edmonds, E. and Candy, L. (2002). Creativity, Art Practice, and Knowledge. In Communications of the ACM, 45, 91-95.

Figallo, C. (1998). Hosting Web Communities: Building Relationships, Increasing Customer Loyalty, and Maintaining a Competitive Edge. John Wiley and Sons, New York.

Fischer, G. (2000). Symmetry of ignorance, social creativity, and meta-design. In Knowledge-Based Systems, 13, 527537.

Gongla, P. and Rizzuto, C. R. (2001). Evolving communities of practice: IBM Global Services experience. In IBM Systems Journal, 40, 842-862.

Graham, G. (1999). The Internet: A Philosophical Enquiry. Routledge, London.

Gross, M. D. (1996). The Electronic Cocktail Napkin- a computational environment for working with design diagrams. In Design Studies, 17, 53-69.

Harrison, S. and Dourish, P. (1996). Re-Place-ing Space: The Roles of Place and Space in Collaborative Systems. In Proceedings of the 1996 ACM conference on Computer supported cooperative workACM, Cambridge MA, USA, pp. 67-76.

Hollan, J. and Stornetta, S. (1992). Beyond Being There. In CHI'92ACM, pp. 119-125.

John-Steiner, V. (2000). Creative Collaboration. Oxford University Press, Oxford.

Kollock, P. (1999). The economies of online cooperation. In Communities in Cyberspace(Eds, Smith, M. A. and Kollock, P.) Routledge, London.

Lawson, B. (1990). How Designers Think: The Design Process Demystified. Butterworths, London.

Mamykina, L., Candy, L. and Edmonds, E. (2002). Collaborative Creativity. In Communications of the ACM, 45, 96-99.

Meyrowitz, J. (1985). No Sense of Place: The Impact of Electronic Media on Social Behavior. Oxford University Press, New York.

Olson, G. M. and Olson, J. S. (2000). Distance Matters. In Human Computer Interaction, 15, 139-178.

Papanek, V. (1972). Design for the Real World. Thames and Hudson, London.

Polanyi, M. (1966). The Tacit Dimension. Doubleday, Garden City, NY.

Shipman III, F. (2001). Seven Directions for Spatial Hypertext Research. In Hypertext 2001: First Workshop on Spatial HypertextACM, Arhus, Denmark.

Shneiderman, B. (2002). Creativity Support Tools. In Communications of the ACM, 45, 116-120.

Shumar, W. and Renninger, K. A. (2002). On Conceptualizing Community. In Building Virtual Communities: Learning and Change in Cyberspace(Eds, Renninger, K. A. and Shumar, W.) Cambridge University Press, Cambridge, UK.

Sperber, D. and Wilson, D. (1986). Relevance: Communication and Cognition. Blackwell, Oxford, UK.

Yamamoto, Y., Nakakoji, K. and Takada, S. (2000). Hands-on representations in a two-dimensional space for early stages of design. In Knowledge-Based Systems, 13, 375-384. 